\title{
Understanding Demographic and Behavioral Mechanisms that Guide Responses of Neotropical Migratory Birds to Urbanization: a Simulation Approach
}

\section{Compréhension des mécanismes démographiques et comportementaux déterminant la réaction des oiseaux migrateurs néotropicaux à l'égard de l'urbanisation : une approche par simulation}

\author{
Daniel P. Shustack $^{1}$ and Amanda D. Rodewald ${ }^{1}$
}

\begin{abstract}
Although studies often report that densities of many forest birds are negatively related to urbanization, the mechanisms guiding this pattern are poorly understood. Our objective was to use a population simulation to examine the relative influence of six demographic and behavioral processes on patterns of avian abundance in urbanizing landscapes. We constructed an individual-based population simulation model representing the annual cycle of a Neotropical migratory songbird. Each simulation was performed under two landscape scenarios. The first scenario had similar proportions of high- and lowquality habitat across the urban to rural gradient. Under the first scenario, avian density was negatively related to urbanization only when rural habitats were perceived to be of higher quality than they actually were. The second landscape scenario had declining proportions of high-quality habitat as urbanization increased. Under the second scenario, each mechanism generated a negative relationship between density and urbanization. The strongest effect on density resulted when birds preferentially selected habitats in landscapes from which they fledged or were constrained from dispersing. The next strongest patterns occurred when birds directly evaluated habitat quality and accurately selected the highest-quality available territories. When birds selected habitats based on the presence of conspecifics, the density-urbanization relationship was only one-third the strength of other habitat selection mechanisms and only occurred under certain levels of population survival. Although differences in adult or nest survival in the face of random habitat selection still elicited reduced densities in urban landscapes, the relationships between urbanization and density were weaker than those produced by the conspecific attraction mechanism. Results from our study identify key predictions and areas for future research, including assessing habitat quality in urban and rural areas in order to determine if habitats in urban areas are underutilized.
\end{abstract}

RÉSUMÉ. Même si des études font souvent état du fait que les densités de nombreux oiseaux forestiers sont négativement liées à l'urbanisation, les mécanismes qui déterminent cette tendance sont mal connus. L'objectif de la présente étude était de simuler une population pour examiner l'influence relative de six processus démographiques et comportementaux sur les patrons d'abondance aviaire dans des paysages urbanisés. Nous avons construit un modèle de population fondé sur l'individu, qui simule le cycle annuel d'un passereau migrateur néotropical. Chaque simulation a été effectuée selon deux scénarios de paysage. Le premier scénario présentait des habitats de qualité élevée ou faible dans des proportions similaires le long du gradient urbain-rural. Selon ce scénario, la densité aviaire n'était négativement reliée à l'urbanisation que dans les cas où les habitats ruraux étaient perçus comme de plus grande qualité qu'ils ne l'étaient en réalité. Dans le second scénario de paysage, la proportion d'habitats de qualité élevée diminuait avec le degré d'urbanisation. Selon ce scénario, chaque mécanisme engendrait une relation

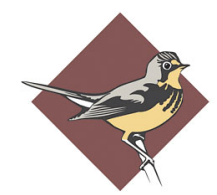

BIRD STUDIES CANADA 
négative entre la densité et l'urbanisation. L'effet le plus fort sur la densité était observé quand les oiseaux sélectionnaient préférablement les habitats dans les paysages où ils étaient nés ou lorsque leur dispersion post-natale était limitée. L'autre patron le plus fort survenait lorsque les oiseaux évaluaient directement la qualité de l'habitat et sélectionnaient correctement les territoires dont la qualité était la plus élevée. Lorsque les oiseaux sélectionnaient les habitats d'après la présence de conspécifiques, la force de la relation densitéurbanisation était seulement du tiers de celle des autres mécanismes de sélection d'habitats; de plus, cette relation survenait seulement sous certains taux de survie des populations. Même si les différences dans la survie des adultes ou des nids entraînaient quand même des densités réduites dans les paysages urbanisés contrairement à une sélection d'habitat aléatoire, les relations entre l'urbanisation et la densité étaient plus faibles que celles produites par le mécanisme d'attraction des conspécifiques. Les résultats de notre étude permettent de faire des prédictions et identifient des voies importantes pour de futures études, y compris l'évaluation de la qualité de l'habitat dans les milieux urbains et ruraux afin de déterminer si les habitats en milieu urbain sont sous-utilisés.

Key Words: conspecific attraction; dispersal; habitat selection; idealfree distribution; neotropicalmigrant; population simulation; underutilized resource; urbanization; urban gradient

\section{INTRODUCTION}

One of the most commonly described consequences of urban development to animal communities is a change in avian distribution (Marzluff et al. 2001). One particularly striking pattern is that many Neotropical migrants have their lowest probabilities of occurrence and densities in the most urban areas and most intensive land uses (Lancaster and Rees 1979, Beissinger and Osborne 1982, Blair 1996, Germaine et al. 1998, Dunford and Freemark 2004, Palomino and Carrascal 2006). This negative response to urbanization has also been observed in landscapes with similar amounts of forest cover, suggesting that the amount of habitat area itself also does not appear to be driving this pattern (Rodewald and Bakermans 2006). Although ecologists have generally discussed how urban habitats may lack appropriate vegetation structure, support higher levels of predators, lack sufficient food resources, have high levels of intra- or interspecific competition, or have high levels of direct or indirect human disturbance (Friesen et al. 1995, Rotterborn 1999, Chace and Walsh 2006), the causes underlying negative responses to urbanization are not well understood. Ultimately, a mechanistic understanding is necessary to guide conservation efforts most effectively in urban landscapes.

Two broadly defined processes can lead to varying densities among habitat patches. First, different densities among patches can result when individuals actively select certain patches. Selection may reflect different quality of patches, or alternatively, the selection might derive from more subtle ecological or social features that are not closely linked to habitat quality. In the context of urban landscapes, Neotropical migrants may innately prefer certain landscape features and thus be more likely to select forests in rural landscapes than forests in urban landscapes, irrespective of the habitat quality of forests in urban areas (Bolger et al. 1997). Second, in the absence of differential movements to and selection for patches, varied demographic rates would lead to different densities in each patch. For example, patches with higher birth rates and lower death rates should accumulate individuals faster than patches with lower birth and higher death rates. Habitat quality will influence directly or indirectly (i.e., through interaction with bird quality) the demographic success of an individual settling in a given patch (sensu Fretwell and Lucas 1970, Johnson 2007). Because Neotropical migrant birds are highly mobile (Greenwood and Harvey 1982, Alderman et al. 2005, Dale et al. 2006, Walters 2007), dispersal of offspring and adults is likely to be important in influencing the distribution of birds across an urban to rural gradient.

In this study, we evaluated six demographic and behavioral processes that have been suggested to be important contributors to the frequently reported pattern of reduced densities of Neotropical migratory birds in urban landscapes. To do this, we created an individual-based population simulation model based on a Neotropical migratory songbird. 
The purpose of our study was to gain insights into the relative effects of each mechanism on generating a relationship between bird density and urbanization, rather than for making specific predictions about the strength of association between urbanization and bird density.

\section{METHODS}

\section{Conceptual Model}

We considered a hypothetical bird species that breeds in discrete habitat patches and exhibits an annual reproductive cycle, loosely basing our model on the life history of the Acadian Flycatcher (Empidonax virescens) (Whitehead and Taylor 2002, Bakermans and Rodewald 2006, Rodewald and Shustack 2008a). Individual birds selected patches in which to nest. All individuals could attempt up to four nests, but stopped nesting after two were successful. Each successful brood produced, with equal probability, either one or two female fledglings, based on the typical clutch sizes for Acadian Flycatcher of three eggs (Whitehead and Taylor 2002). After all breeding ceased, individuals lived or died, and individuals either dispersed to a different patch or remained in their same patch before the subsequent breeding season. Migration is implied only (Fig. 1). For simplicity, we assumed the population is socially monogamous and we only modeled females.

\section{Baseline Model}

Each simulation began with 100 equal individuals (i.e., territories about $25 \%$ full). Individuals had no ability to assess perceived habitat quality (see below for distinctions between intrinsic, realized, and perceived habitat quality), thus each individual had an equal probability of selecting any unoccupied territory. In other words, in the baseline model, the perceived habitat quality is zero for all territories. Therefore, probability of selecting any other level of urbanization was in proportion to the unoccupied territories in that level of urbanization.

We directly related nest survival to intrinsic habitat quality. At the start of each simulation, we calculated the daily nest survival rate (DNSR) necessary to maintain a stable population under a deterministic scenario. Then we estimated the average realized habitat quality of occupied patches. We set the DNSR for the average occupied habitat quality equal to the DNSR needed for a stable population. For the baseline model, we chose to relate DNSR to habitat quality for three reasons. First, DNSR is a commonly measured fitness metric in bird studies. Second, we reasoned that habitat quality might be more directly related to DNSR than other fitness metrics such as adult survival (i.e., adults could maintain their survival by leaving a patch of low habitat quality). Third, adult survival on the breeding grounds tends to be high (Sillet and Holmes 2002). For each 0.1 deviation in habitat quality from the "average" habitat quality, we adjusted the DNSR by $10 \%$ on a log-odds scale, which bound DNSR by 0 and 1 . Each individual experienced a probability of reproductive success directly related to the realized habitat quality of its territory. During each simulation, we adjusted, if necessary, the "average" occupied habitat quality upward or downward slightly in order to maintain an approximately constant population size. This scheme generated source-sink population dynamics (Pulliam 1988) where some patches were sinks and other sources. Although the population size could change from year to year, the process of annually adjusting the "average" habitat quality led to a longterm average population growth rate of about 1 . We simulated an approximately stable population to prevent habitat saturation and population extinction, both of which would produce no relationship between urbanization and density. In other words, overall population size remained approximately the same (about one-quarter of available territories occupied), but the density per patch (i.e., how the population is distributed among patches) varied, allowing us to examine how bird density related to urbanization.

Based on the habitat-specific DNSR, we determined the cumulative probability of each female producing zero, one, or two successful nests, assuming a 29day nesting cycle. We then used a random number drawn from a uniform distribution to determine how many successful nests each individual produced. Random numbers that fell between zero and the probability of producing one successful nest resulted in assigning that female no successful nests. Random numbers that fell between the probability of producing one successful nest and the two successful nests resulted in that female having one successful nest, and so on. 
Fig. 1. Conceptual model of the annual cycle for a hypothetical migratory songbird. The migratory period is not explicitly modeled.

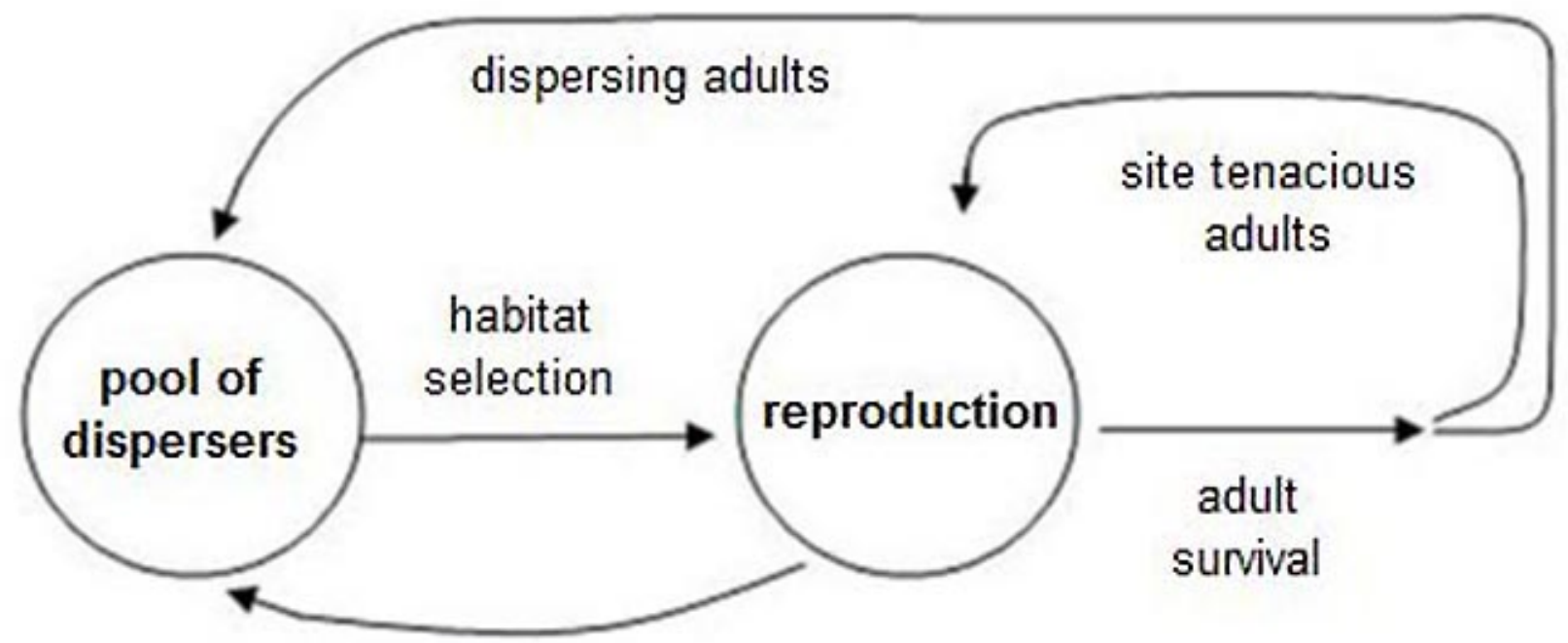

juvenile survival

Probability of adult survival and juvenile survival was constant across the population. Baseline adult survival probability was 0.6 and juvenile survival probability was set at one-half of adult survival (Donovan and Thompson 2001 and references therein). This baseline value is high compared with our estimates of apparent survival based on field data for adult female Acadian Flycatchers (0.23, 95\% CI (0.13-0.38), but is within the range for adult male Acadian Flycatchers $(0.53$, 95\% CI (0.420.64), Rodewald and Shustack 2008a). However, these field-based estimates are for apparent survival (i.e., survival estimates includes death and permanent emigration from our search areas), suggesting that real survival would be higher. Because adult survival may vary across populations and species, in four of six simulated mechanisms, we examined the sensitivity of the model outputs to different levels of adult survival.

Several rules governed dispersal and site fidelity. All surviving juveniles entered the pool of dispersers (Greenwood and Harvey 1982). Based on the literature showing that successfully reproducing adult songbirds exhibit high site fidelity (Haas 1998), all surviving adults that produced at least one offspring were assigned to their previous territory. Adults that did not produce offspring were dispersers. After site-faithful adults returned to their territories, the dispersers were placed in random order. Once an individual selected a territory, it would remain on that territory for that breeding season. Because individuals who successfully reproduced and survived to the following breeding season returned to their previous territory, the baseline model itself has a capacity to produce differences in densities across patches with differing adult and nest survival rates. Although the effect of site fidelity mediated by nest survival and adult survival can obviously lead to differences in density in the simple two-patch case (Appendix 1), it is less apparent what effect this mechanism can have in a multipatch scenario such as the one we considered. We specifically simulated two mechanisms in order to investigate the potential of demographically mediated site fidelity to generate a relationship between bird density and urbanization. In addition, because successful breeding is known to promote site fidelity among songbirds, we incorporated site fidelity into the 
baseline model and it is, therefore, present in all mechanisms we considered.

\section{Landscape Scenarios}

To assess how the different mechanisms are influenced by heterogeneity in habitat quality, we constructed two generalized landscapes. Both scenarios had less habitat in more urban areas, but the two scenarios differed in the distribution of highand low-quality habitats. The first scenario (scenario: "increasing quality") contained more habitat patches of higher quality when urbanization was lower (e.g., more rural). In the second scenario, the quality of the habitat patches was constant across all levels of urbanization (scenario: "equal quality") (Fig. 2). The explicit landscape comprised only potential breeding patches of varying quality within five different levels of urbanization, reflecting an urban to rural gradient (McDonnell and Pickett 1990). For our purposes we implicitly defined these five levels on a scale of one (most urban) to five (least urban or most rural), although these five levels could also represent some other sort of gradient. Hereafter, we refer to these five levels as "urbanization levels." The "increasing quality" scenario had 96 patches and the "equal quality" scenario had 103 patches; the exact number of patches was not equal between scenarios in order to accommodate the specified proportions of each level of intrinsic habitat quality (see below).

The landscape was spatially explicit in only one dimension; patches are equidistant to the next highest and lowest urbanization level (i.e., patches in level three are equally close to all patches in level two and level four). All movements between patches within an urbanization level were "free" (sensu Fretwell and Lucas 1970), and except for one mechanism, all movements across urbanization levels were "free" as well. Urban land development can produce various types of patch sizes and arrangements that may be influenced by specific topographic and social factors (Weng 2007). However, to simplify the interpretation of the results, we made the assumption of equal patch sizes. Each patch could support up to four breeding females (reflecting the small patch sizes of Rodewald and Shustack (2008a)).

We used a scale from 0 to 1 incremented by 0.1 to define intrinsic habitat quality. We assumed that the lowest quality habitat (i.e., 0) would occur in the greatest proportion, the highest quality habitat (1.0) would occur in the lowest proportion, and that the proportions of habitat in the intervening levels of habitat quality would occur in monotonically decreasing proportions such that the total sum of habitat proportions of each habitat quality summed to one. We used this framework to reflect the assumption that high-quality habitat is generally limiting compared with low-quality habitat, an assumption that has been used in other modeling contexts (Kristan 2003).

We defined habitat quality in three ways. The intrinsic habitat quality is the value assigned to the patch. Realized habitat quality is the level of habitat quality that was related to a particular level of fitness after accounting for density-dependent declines in habitat quality that result from the presence of conspecifics (sensu Fretwell and Lucas 1970). Intrinsic and realized habitat quality differed in only one simulation ("selection based on habitat quality when prior colonizers lower the realized habitat quality," see below). In contrast, perceived habitat quality is the level of habitat quality as perceived by a bird when making habitat selection decisions. Perceived habitat quality is used to incorporate cues (e.g., presence of conspecifics or level of urbanization into habitat selection) cues that may not be directly related to habitat quality. In all mechanisms, individuals made territory selections based on perceived habitat quality. For example, a bird may perceive a particular territory as being of a certain quality due to some cue, but after selection of that territory, the bird will realize a demographic rate related to the realized habitat quality.

We bounded intrinsic, realized, and perceived habitat quality by 0 and 1 , regardless of the number of modifications made to both realized and perceived habitat quality (see mechanisms below for explanation of modifications). Depending on the mechanism, patches could vary in their intrinsic, perceived, and realized habitat quality, but all territories within a patch had the same intrinsic and realized quality. For one simulation ("selection based on habitat quality when prior colonizers lower the realized habitat quality," see below), the perceived quality of each territory within a patch was modified as each subsequent bird settled there. 
Fig. 2. Number of patches at each urbanization level used in the two landscape scenarios. Number 1 represents patches surrounded by the greatest amounts of urbanization and 5 the least (i.e., most rural). The area contained by the uppermost line indicates the total number of sites in that urbanization level. The different shading patterns indicate how that total number of sites is divided between patches of different habitat qualities. Habitat quality is defined in 0.1 increments from 0.0 to 1.0. Fig. A shows the landscape scenario: increasing quality. Fig. B shows the landscape scenario: equal quality.
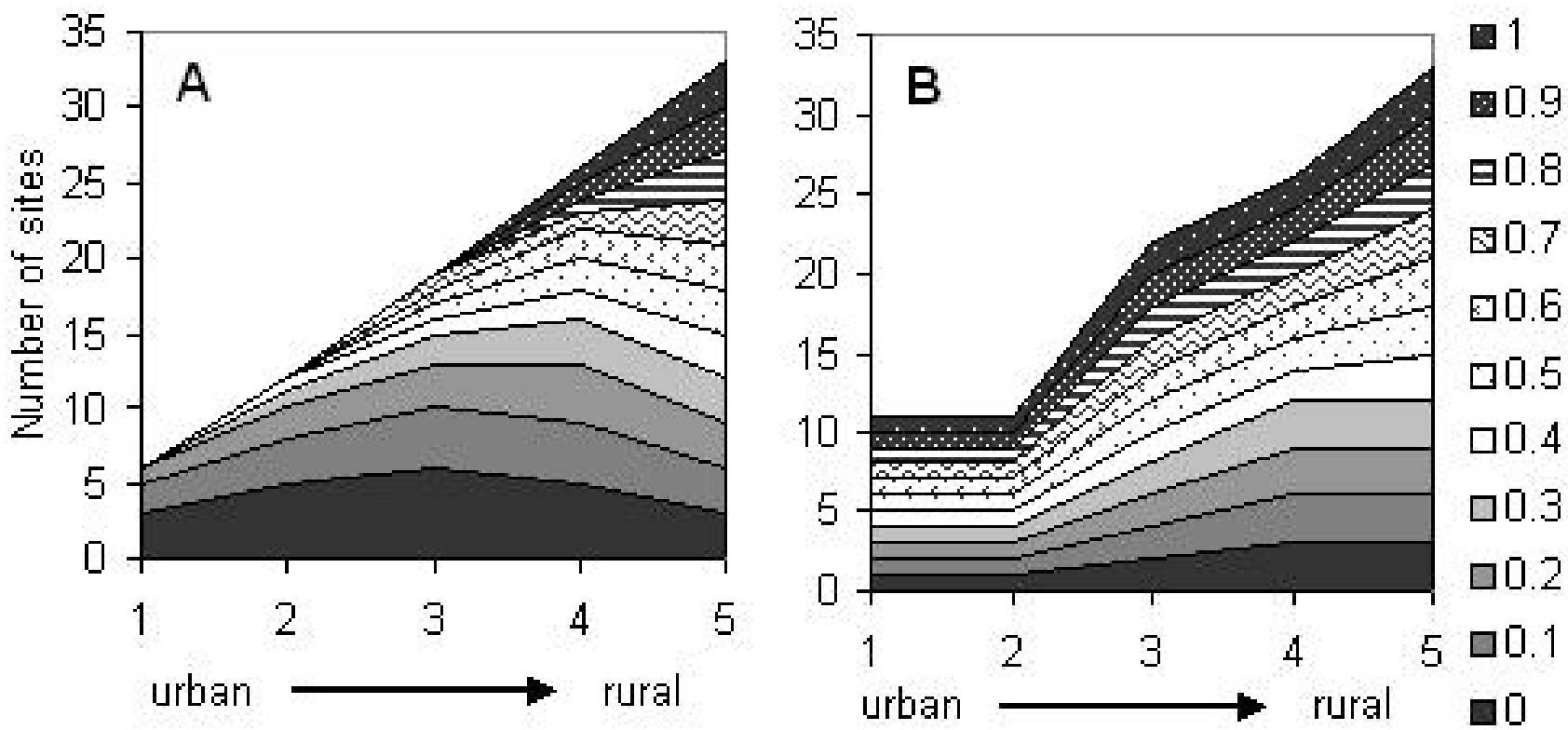

\section{Mechanisms}

We varied the baseline model in order to represent six different mechanisms that might lead to a relationship between urbanization and bird density. Each mechanism was run over a range of conditions to assess the sensitivity of model outputs to variation of certain parameters that we considered most likely to vary in Acadian Flycatcher populations or other avian species or to influence the outcome of the mechanism.

\section{Variation of nest survival with realized habitat quality}

Nest predation has been suggested as one factor that can influence whether birds are found in urban and suburban areas (Friesen et al. 1995, Schochat et al. 2006). This mechanism incremented the percent change in DNSR on a log-odds scale from 0 to 40 by $10 \%$. Increasing the percent change in DNSR effectively increases the heterogeneity of habitat quality between patches by making the higherquality patches have very high DNSR and the lowquality patches have very low DSNR, resulting in an increasingly steep slope between them. We have no information about the actual pattern in how DNSR varies in relation to habitat quality so this is a theoretical relationship, and we examined a range of values to determine the effect of increasing heterogeneity. This mechanism determines what distribution of birds would result based on the baseline site-fidelity rule coupled with increasing heterogeneous habitat quality manifested through nest survival rates. We also do not specify what may cause the lower DNSR, but predation rates due to altered predator community, changes in food availability due to pollution or vegetation communities, or competition with resident bird species are all possible factors that could lead to 
lower DNSR. We examined the effects of heterogeneity in DNSR over the range of adult survival from 0.45 to 0.75 by increments of 0.05 .

\section{Variation in adult survival with realized habitat quality}

Lower adult survival in more urban areas has also been implicated in causing reduced densities of some bird species in urban areas (Friesen et al. 1995, Schochat et al. 2006). In this simulation, we related probability of adult (and by extension juvenile) survival to habitat quality. We set the population average adult survival to the average occupied habitat quality (found as above for the baseline model in the context of DNSR). Then we incremented the adult survival up (or down) by a set amount for each increase (or decrease) in habitat quality of 0.1 . The increase or decrease was linked directly to the probability of adult survival (i.e., not log-odds as with DNSR). We bounded adult survival probability for any given patch to 0.1 and 0.95. Any adult survival values that fell outside these bounds were set to the maximum or minimum respectively. As with DNSR, we adjusted the "average" habitat quality following each breeding iteration to maintain an approximately stable population. Source-sink population dynamics are generated by incorporating adult survival as well as the baseline values in DNSR. We considered increases in probability of adult survival of $0-0.1$ by increments of 0.02 for each increase in habitat quality of 0.1 . This simulation is similar to the previous one in generating increasing disparity in adult survival between patches of different quality, but has the potential to cause individuals to collect in certain patches through differential survival of adults and through site fidelity of successful breeders. We simulated this mechanism at the average population adult survival rate of $0.45,0.6$, and 0.75 (but recall there is heterogeneity in adult survival across habitat patches based on habitat quality).

\section{Selection based only on prior colonizers}

Conspecific attraction suggests that presence of prior colonizers leads to an increase in perceived habitat quality (i.e., there is an attractive effect of prior colonizers). Conspecifics may serve as a reliable cue for quality habitat and have been suggested as influencing the distributions of birds (Friesen et al. 1995, Nol et al. 2005, reviewed in Ahlering and Faaborg 2006). We simulated habitat selection where conspecifics were the only cues used for habitat selection. This mechanism has the potential to cause individuals to collect in certain patches of higher quality because higher-quality patches are more likely to retain individuals that successfully reproduce and return to the patch. Then, in the subsequent year, those individuals attract more individuals to these patches. If there are more patches of higher quality in more rural urbanization levels, this could lead to a relationship between bird density and urbanization level. We simulated prior colonizers having an attractive effect, a repulsive effect, and no effect on territory selection. We examined this pattern on adult survival values of $0.45,0.6$, and 0.75 .

\section{Selection based on habitat quality when prior colonizers lower the realized habitat quality}

As more individuals settle at a site, the habitat quality experienced by each inhabitant may decrease (i.e., ideal free distribution, Fretwell and Lucas 1970). We simulated a decrease in realized habitat quality by varying the amount of decrease in realized habitat quality from 0 to 0.4 for each additional individual who settles at that patch. When only a single bird is at a patch, that individual experiences a realized habitat quality equal to the intrinsic habitat quality. A second settler to the patch reduces realized habitat quality experienced by all individuals in that patch. Thus, this second settler selects the habitat based on what would be the lower habitat quality after two birds occupied the site. Even though the first settler selects the habitat when the perceived habitat quality is equal to the intrinsic habitat quality, it ultimately experiences a realized habitat quality influenced by the final density of that patch. We included this mechanism to demonstrate the most adaptive distribution possible due to individuals occupying the highest quality patches available. In addition, this mechanism can lead to higher densities in rural areas if rural areas contain more high-quality patches than urban areas and birds are able to select those high-quality patches, a possibility that seems particularly likely.

Because birds are unlikely to assess habitat quality perfectly (Gilroy and Sutherland 2007), we incorporated the possibility for errors in assessment of habitat quality. We assumed that a bird could assess all available territories but their assessment of habitat quality was imperfect. First, we ordered the available territories based on perceived habitat quality. We called this the "actual rank." Then we 
generated a random ordering of territories and called this the "random rank." The ability to accurately assess perceived habitat quality was assigned a value between zero (no ability to assess quality) and one (perfect ability to assess quality) but was constant over all individuals in a given simulation. We then generated a composite ordering by weighting the actual and random orders by the selection ability (i.e., final rank $=$ (actual rank $\mathrm{x}$ selection ability) + (random rank x 1 - selection ability)). This is a simplistic way to incorporate assessment errors of habitat quality without specifying the basis of those errors, a topic requiring its own study. The top-ranking territory based on the final rank was the territory selected by that individual. This process was repeated for each individual in order to incorporate prior settlers into the assessment of habitat quality.

\section{Overvaluing of rural habitat quality}

We considered that birds might perceive habitat quality as being influenced by the degree of urbanization around each site. For instance, a patch might be perceived as being of higher quality if it is in a rural landscape as opposed to an urban landscape irrespective of realized habitat quality (Friesen et al. 1995, Bolger et al. 1997). Urban patches may be valued less if presence of other species, urban noise or lighting, or other features, lower the perceived habitat quality of a patch in an urban area but do not actually affect the fitness prospects of an individual that uses that patch. We simulated the overvaluation of rural habitat by adding a fixed amount to the perceived habitat quality for each increase in the level of urbanization. We considered increases in perceived habitat quality of $0,0.05,0.1,0.15$, and 0.2 . For example, for an overvaluation of 0.1 , a patch of quality 0.5 at position 1 would be perceived as having a habitat quality of $0.6,0.7,0.8$, and 0.9 at urbanization levels $2,3,4$, and 5, respectively. We treated this as an effect on perceived quality (i.e., cue used to select the territory) whereas the DNSR realized by using that territory was based on the realized territory quality (i.e., 0.5 in the previous example). As in other simulations, we constrained the perceived habitat quality to 1 so any perceived habitat quality values greater than 1 were set to 1 . We examined the effects of this mechanism over the range of selection abilities (0-1). Selection ability was simulated in the same way as the previous mechanism.
Selection of natal urbanization level and limited dispersal

A tendency for individuals to stay in the same urbanization level in which they were raised could result from several processes. First, individuals may actively select areas similar to or near their natal urbanization levels. In the context of our model, this would suggest that the level of urbanization in which individuals were fledged becomes their preferred one (Davis and Stamps 2004, Stamps and Swaisgood 2007). Second, if dispersers are physically or psychologically limited in their ability to move away from their natal area, this would also lead to a propensity for individuals to stay in their natal urbanization level. Due to our model structure, these two mechanisms are modeled the same way and we cannot specifically separate them. This mechanism can lead to an association between bird density and urbanization by collecting birds in areas where reproductive output is higher if those areas tend to be in more rural areas.

We defined the probability that an individual would move one urbanization level (i.e., equal probability of moving either up or down one urbanization level). A probability of 0 would indicate that there was no probability that an individual would leave its natal level of urbanization and a probability of 1 indicates that all urbanization levels were equally likely to be selected. Based on the probability of moving one urbanization level, we calculated the probability of moving to any of the urbanization levels relative to the individual's urbanization level occupied in the previous year. Then we drew a random number and compared this with the cumulative probability of making a certain number of moves in urbanization levels to determine the number of moves in urbanization levels made by the individual. We then randomly selected an available territory that was that number of urbanization levels away. Thus, territory selection was random except for a propensity to stay in the natal level of urbanization, or, once an individual moved, a propensity to stay in its new urbanization level. We set the probability of moving from 0 to 1 by increments of 0.1 and examined the sensitivity of movement probability over three levels of adult survival, $0.45,0.6$, and 0.75 to the model outputs. 


\section{Data analysis}

In each run of the simulation, the annual cycle was repeated for 11 years. Eleven years was sufficient time to allow for numerical stabilization given that the adult annual survival probabilities used in the simulations ranged between 0.45 and 0.75 (corresponding to life expectancies of 1.3 and 3.5 years, respectively). We also examined output from several of the simulations after 25 years; results did not differ appreciably between 25 and 11 years. After individuals were distributed to their territories at the beginning of year 12, we calculated the density of individuals in each patch. We used PROC REG (SAS 2002) to calculate the slope of the leastsquares regression line between the urbanization level and bird density in each patch. We report the average slope value for the 20 times each simulation was performed. Although a linear model may not have provided the best fit to the simulated distributions in all cases, we used the linear model in all cases in order to have a consistent and easy metric to compare the relative effects of each mechanism. This simulation model was coded in SAS version 9.1 and run between June 2007 and October 2007 on desktop PCs running Windows 2000 or XP operating systems.

\section{RESULTS}

When the simulations were performed on the landscape scenario with equal habitat quality across all urbanization levels (Fig. 2B), only the mechanism "overvaluing of rural habitat quality" produced appreciable relationships between bird density and level of urbanization (Fig. 3D). Therefore, below we only describe the key results from the simulations performed on the landscape with increasing quality (e.g., Fig 2A).

The mechanism "selection of natal landscape or limited dispersal" produced the strongest relationship between bird density and urbanization, but the strength of the slope dropped off quickly as birds were more likely to move between levels of urbanization (Fig. 3E). The mechanisms that produced the next strongest relationships were the ones that included direct evaluation of habitat quality. The mechanism "selection based on habitat quality when prior colonizers lower the realized habitat quality" produced high slope values even at low levels of ability to assess habitat quality (Fig. $3 \mathrm{~A})$. As the effect of prior colonizers on habitat quality increased, the strength of association between bird density and urbanization decreased, indicating a more equal distribution of birds across the different levels of urbanization (Fig. 3A). The mechanism "overvaluing of rural habitat quality" produced slightly stronger slopes, but these strong slopes were also apparent even at lower levels of ability to differentiate habitat quality (Fig. 3C). Conspecific attraction, simulated through the mechanism "selection based only on prior colonizers," generated slope values more than twice the slope values produced when there was no conspecific attraction (neutral or baseline model), however, this was not true at the lowest level of adult survival (0.45) where slope values were nearly 0 for conspecific attraction, avoidance, and neutral response (Fig. 4E). Finally, the two demographic only mechanisms, "variation of nest survival with realized habitat quality" (Fig 4A) and "variation in adult survival with realized habitat quality" (Fig. 4B) also generated small slopes with increasing slope values with increasing heterogeneity in adult survival, but increasing heterogeneity in nest survival did not lead to apparently greater slopes.

\section{DISCUSSION}

The objective of our study was to assess the relative influence of demographic and behavioral processes on landscape-scale patterns of avian distribution in urbanizing landscapes. Using a population simulation model, we identified various conditions under which each mechanism would generate a negative association between bird density and urbanization. A key insight from this study was that when habitat quality was similar across an urban to rural gradient, only one mechanism, "overvaluing of rural habitat quality," was able to generate higher densities in more rural landscapes. Yet, if habitat quality declined with increasing urbanization, all of the mechanisms we considered were able to generate lower densities in urban areas. As a general rule, habitat selection mechanisms elicited stronger responses than demographic mechanisms.

Although demographic processes have been invoked to explain the patterns of bird density over an urban to rural gradient, our results suggest that demographic mechanisms coupled with site fidelity of successful breeders seem unlikely to explain the frequently observed relationship between urbanization and density. Overall, we found very weak patterns 
Fig. 3. A-F. Average slope estimates (+/- $1 \mathrm{SE}$ ) of 20 repetitions of the simulations reflecting three different mechanisms (labeled on left-hand side) in two landscape scenarios (labeled at top.) See text for descriptions of mechanisms.

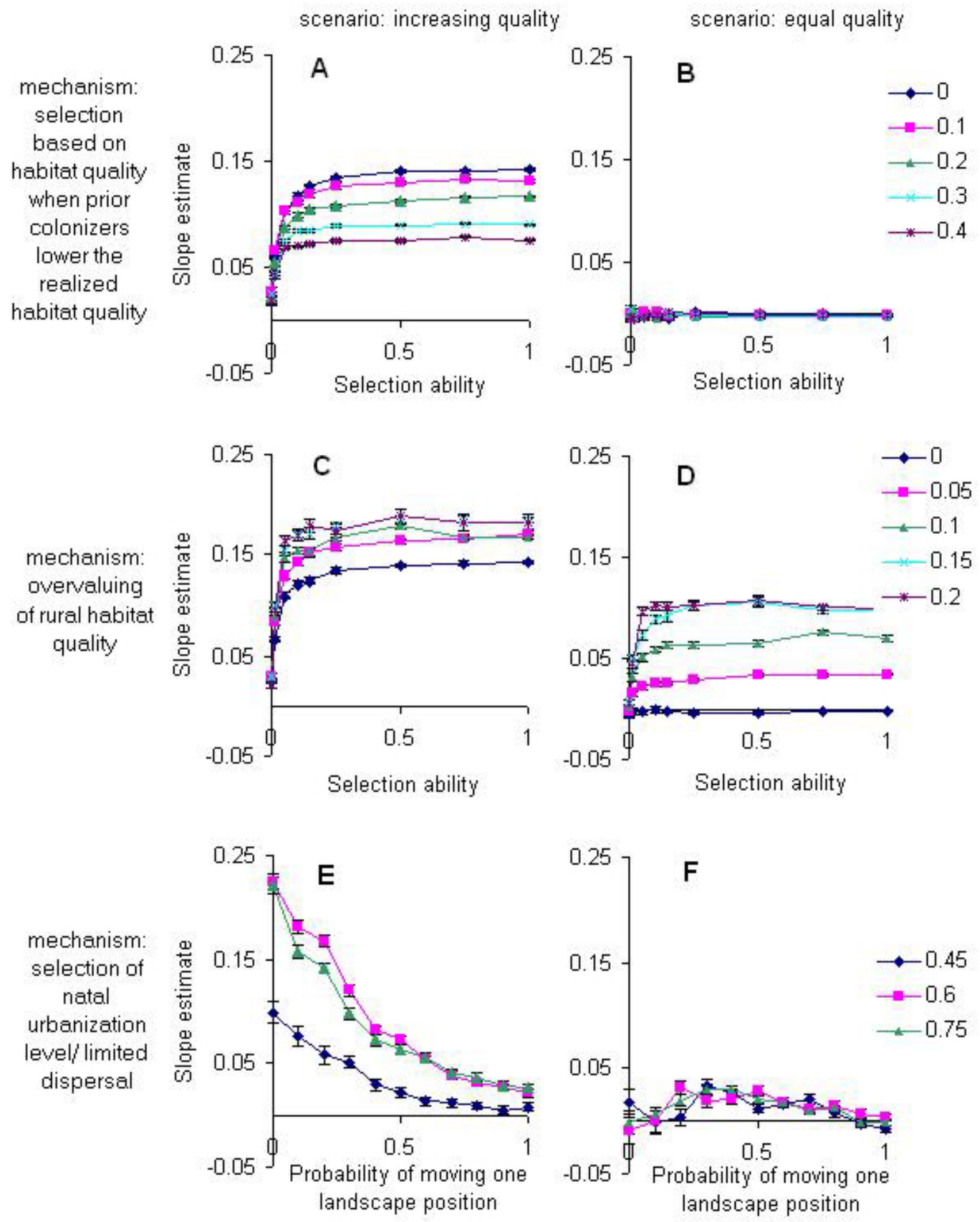


Fig. 4. A-F. Average slope estimates (+/- $1 \mathrm{SE}$ ) of 20 repetitions of the simulations reflecting three different mechanisms (labeled on left-hand side) in the two landscape scenarios (labeled at top). See text for descriptions of mechanisms.

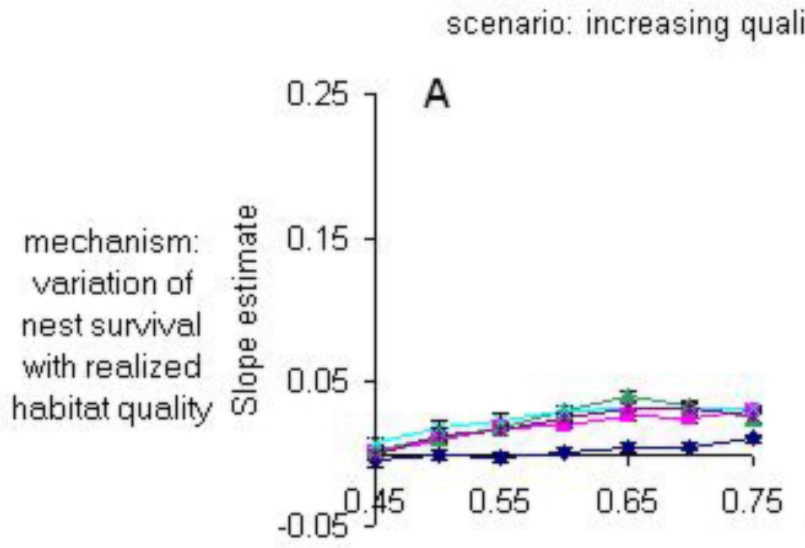

Population adult survival
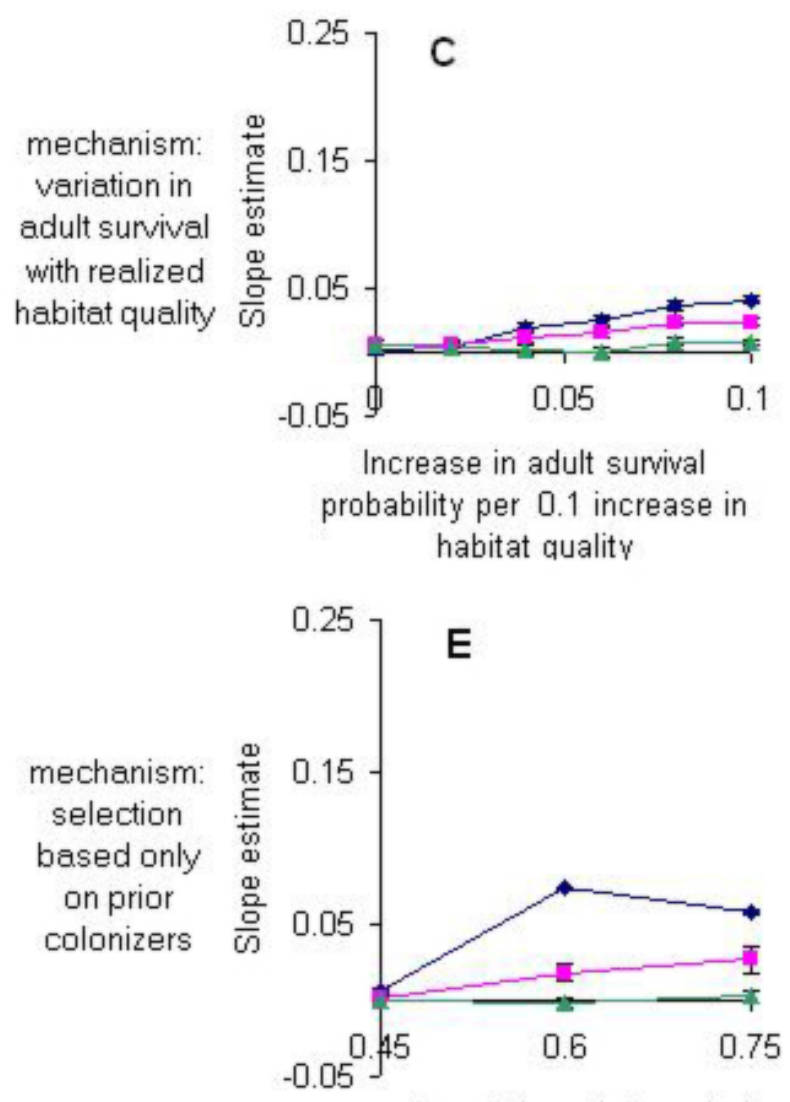

Population adult survival scenario: equal quality

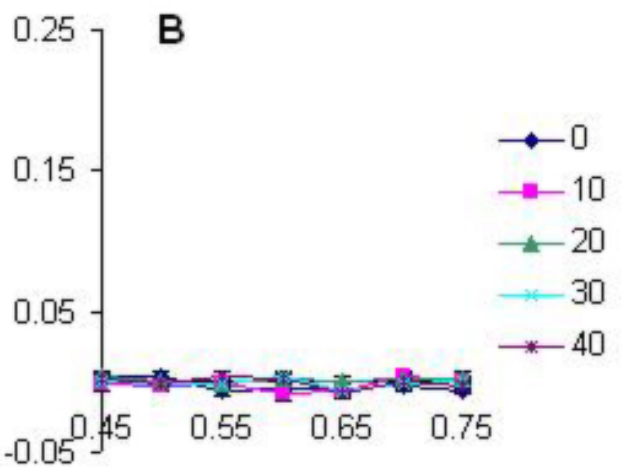

Population adult survival
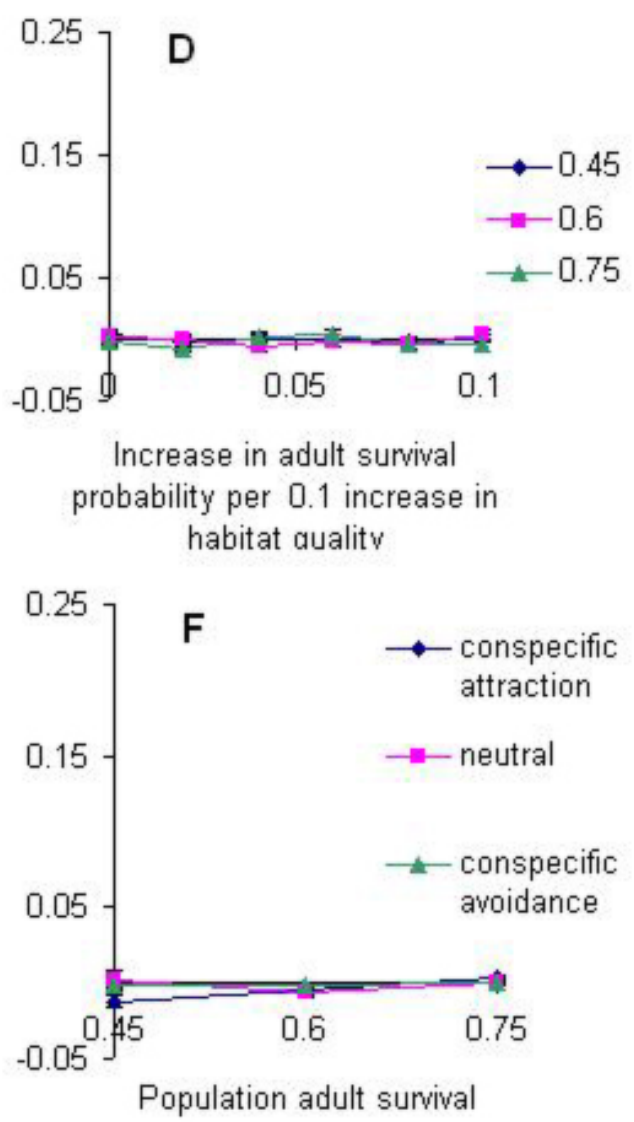
between urbanization and density, regardless of the degree of differences in nest survival and adult survival across different levels of habitat quality. Furthermore, we suspect that the small slopes generated in our simulations would likely be undetectable in the field due to imperfect detection of individuals in the field and difficulty in obtaining adequate sample sizes. Although survival has been suggested to be a proximate mechanism of reduced densities of certain sensitive species in urban areas (Donnelly and Marzluff 2004, Shochat et al. 2006), we interpret our results to suggest differences in nest or adult survival are ineffective to maintain lower densities in urban forests, particularly for highly vagile species.

Why did the demographic mechanisms not produce a stronger relationship between urbanization and density? Demographic simulations increased bird density in rural areas only if individuals survived, successfully reproduced, and returned to their rural territories at higher rates compared with urban territories. Because of the way we maintained an approximately stable population in our model, adult survival was high when nest survival was low, and vice versa. Therefore, the number of site-faithful individuals was always relatively low (either through few successful adults or fewer surviving successful adults) and the dispersers ended up in available territories in proportion to their availability, weakening any pattern generated by site-faithful individuals. The simple site-fidelity decision rules that we modeled may have obscured the influence of survival. Our simulations limited site fidelity to adults fledging at least one host young (Switzer 1993, 1997), which is a commonly used assumption in habitat selection and population models (Donovan and Thompson 2001, Doligez et al. 2003), given that site tenacity has been associated with reproductive success (Greenwood and Harvey 1982, Haas 1998). However, more complex sitefidelity decision rules may also contribute to observed urbanization density relationships. For instance, in our field study of Acadian flycatchers, we found evidence for different site-fidelity rules because rural birds were more likely than urban birds to display site fidelity despite nest failure (Rodewald and Shustack 2008a).

Although demographic factors alone were unable to generate strong differences in density, when demographic differences were combined with the propensity of individuals to remain in their natal areas, demographic factors produced the strongest relationships we observed in any of our simulations, but only when rural landscapes contained higher proportions of high-quality habitats. Our simulations reflecting philopatry for the natal level of urbanization can be interpreted in three different ways. First, landscape philopatry could reflect an active preference for patches surrounded by certain landscape characteristics present in their natal areas. This interpretation may be appropriate for vagile species such as Neotropical migrants that may have a strong selection preference (inherited or learned) for patches based on the surrounding landscape. Second, landscape-level philopatry could reflect physical constraints on dispersal imposed by limited vagility, which may describe movements by nonmigratory birds or flightless species. Third, landscape-level philopatry might reflect a behavioral constraint where dispersers initiate habitat selection from the location they occupied in the previous breeding season (Dale et al. 2005). Our finding that limited movements can greatly influence bird distributions is consistent with other studies that suggest that movement behaviors, including natal dispersal, are important drivers of organism distributions across landscapes (Westerberg and Wennergren 2003, Tischendorf et al. 2005). Although migratory birds are capable of breeding and dispersing dozens of kilometers (Paradis et al. 1988, Dale et al. 2006) or even hundreds of kilometers (Girvan et al. 2007) from their natal site, behavioral limitations may influence actual dispersal at local levels (Belisle et al. 2001, Fraser and Stutchbury 2004). Clearly, further research on avian dispersal is needed in order to understand factors that influence bird distributions across heterogeneous landscapes such as urban to rural gradients.

Our simulations demonstrate that under certain situations conspecific attraction can result in lower bird densities in urban areas. This pattern was particularly evident at moderate levels of adult survival and only in the landscape scenario, where more rural areas had higher-quality habitat than urban areas. Much attention has been paid recently to the role of conspecific attraction in habitat selection (Stamps 1988, Reed and Dobson 1993, Ward and Schlossberg 2004, Ahlering and Faaborg 2006), and our results suggest that a simple decision rule of settling areas occupied by conspecifics can help generate higher densities of Neotropical migrants in rural landscapes in some situations.

Some researchers have suggested that cues for habitat selection and fitness might be decoupled in urban areas (Bolger et al. 1997). Instead, the 
landscape itself may be a cue for habitat selection (Hilden 1965) and individuals may prefer habitats in more rural landscapes even in cases where habitat quality might be similar across the landscape. Furthermore, settlement preferences may stem from general perceptions of the landscape (e.g., the matrix composition; Dunford and Freemark 2004) and not from direct assessments of habitat quality. This is the essence of the "landscape-selection hypothesis" suggested by Bolger et al. (1997), which postulates that selection for a particular landscape may be unrelated to fitness prospects in habitats in those landscapes. Our simulations demonstrated that it is possible to generate a relationship between urbanization and density when habitat quality is similar across the landscape. However, this only occurred if the habitat quality of rural patches was overvalued, reflecting a disconnect between habitat quality and the cue for selection similar to instances of ecological traps. The situation implied in the landscape selection hypothesis is that the cue for high-quality habitat is lost or manipulated due to urbanization. Thus highquality habitat in urban areas may remain underutilized (Gilroy and Sutherland 2007). Individuals may not be deliberately selecting lowquality habitat (ecological traps), but are failing to select high-quality habitat because of the surrounding landscape. Future research should focus on elucidating whether habitats in urban areas represent an underutilized resource or whether urban habitats are lower-quality habitats for Neotropical migrantory birds. In particular, research should better investigate links between fitness, landscape attributes, and smaller-scale habitat features that contribute to habitat quality and may covary with the landscape (Wiens et al. 1993).

We believe that our study suggests several important predictions and areas of future research regarding urbanization and Neotropical migratory birds. Ultimately, understanding the mechanisms that generate bird distributions in relation to urbanization may be important for conserving these species in an increasingly urban world. First, because we found that all mechanisms could produce a negative association between urbanization and bird density when habitat quality is lower in urban areas, it is important to confirm that habitat quality is actually lower in urban areas, an assumption that is seldom tested (but see Marzluff et al. 2001, Rodewald and Shustack 2008a, b). Rather, a negative relationship between urbanization and habitat quality is commonly assumed because of observed bird distributions, yet our results demonstrated that the negative association between density and urbanization can arise even when habitat quality is similar in urban and rural areas. Consequently, an important line of future research will be to ascertain whether urban habitats are underutilized by Neotropical migratory birds due to overvaluing rural habitat quality. Second, because limited dispersal or preference for the natal level of urbanization produced a very strong relationship between urbanization and bird density, a relevant line of research will involve assessing how birds disperse across an urbanizing landscape. Although we cannot identify which particular mechanisms (or combinations of mechanisms) actually operate to generate lower densities of Neotropical migratory birds, we were able to determine the relative influence of six demographic or behavioral processes on patterns of avian abundance in urbanizing landscapes. The results of this research identified several predictions and areas of study that can be pursued in the field.

Responses to this article can be read online at: http://www.ace-eco.org/vol3/iss2/art2/responses/

\section{Acknowledgments:}

Collection of the field data supporting this work was funded by the National Science Foundation (DEB-0340879 to ADR), Ohio Division of Wildlife, Ohio Agricultural Research and Development Center, and The Ohio State University Swank Program in Rural-Urban Policy. This research benefited from discussions with members of the Rodewald lab, especially S. Matthews. T. Waite, W. Thogmartin, and two anonymous reviewers provided valuable comments on earlier drafts of this manuscript. SAS code used to perform the simulations is available from the first author.

\section{LITERATURE CITED}

Alderman, J., D. McCollin, S. A. Hinsley, P. E. Bellamy, P. Picton, and R. Crockett. 2005. Modelling the effects of dispersal and landscape configuration on population distribution and viability in fragmented habitat. Landscape Ecology 20:857-870. 
Ahlering, M. A., and J. Faaborg. 2006. Avian habitat management meets conspecific attraction: if you build it, will they come? Auk 123:301-312.

Bakermans, M. H., and A. D. Rodewald. 2006. Scale-dependent habitat use of Acadian Flycatcher (Empidonax virescnes) in central Ohio. Auk 123:368-382.

Beissinger, S. R., and D. R. Osborne. 1982. Effects of urbanization on avian community organization. Condor 84:75-83.

Belisle, M.,A. Desrochers, and M. J. Fortin. 2001. Influence of forest cover on the movements of forest birds: a homing experiment. Ecology 82:18931904.

Blair, R. B. 1996. Land use and avian species diversity along an urban gradient. Ecological Applications 6:506-519.

Bolger, D. T., T. A. Scott, and J. T. Rotenberry. 1997. Breeding bird abundance in an urbanizing landscape in coastal southern California. Conservation Biology 11:406-421.

Chace, J. F., and J. J. Walsh. 2006. Urban effects on native avifauna: a review. Landscape and Urban Planning 74:46-69.

Dale, S., A. Lunde, and O. Steifetten. 2005. Longer breeding dispersal than natal dispersal in the ortolan bunting. Behavioral Ecology 16:20-24.

Dale, S., O. Steifetten, T. S. Osiejuk, K. Losak, and J. P. Cygan. 2006. How do birds search for breeding areas at the landscape level? Interpatch movements of male ortolan buntings. Ecography 29:886-898.

Davis, J. M., and J. A. Stamps. 2004. The effect of natal experience on habitat preferences. Trends in Ecology and Evolution 19:411-416.

Doligez, B., C. Cadet, E. Danchin, and T. Boulinier. 2003. When to use public information for breeding habitat selection? The role of environmental predictability and density dependence. Animal Behaviour 66:973-988.

Donnelly, R., and J. M. Marzluff. 2004. Importance of reserve size and landscape context to urban bird conservation. Conservation Biology 18:733-745.
Donovan, T. M., and F. R. Thompson, III. 2001. Modeling the ecological trap hypothesis: a habitat and demographic analysis for migrant songbirds. Ecological Applications 11:871-882.

Dunford, W., and K. Freemark. 2004. Matrix matters: effects of surrounding land uses on forest birds near Ottawa, Canada. Landscape Ecology 20:497-511.

Fraser, G. S., and B. J. M. Stutchbury. 2004. Areasensitive forest birds move extensively among forest patches. Biological Conservation 118:377387.

Fretwell, S. F., and J. Lucas, J. L. 1970. On territorial behavior and other factors influencing habitat distribution in bird. I. Theoretical development. Acta Biotheoretica 19:16-36.

Friesen, L. E., P. F. J. Eagles, and R. J. Mackay. 1995. Effects of residential development on forestdwelling neotropical migrant songbirds. Conservation Biology 9:1408-1414.

Germaine, S. S., S. S. Rosenstock, R. E. Schweinsburg, and W. S. Richardson. 1998. Relationships among breeding birds, habitat, and residential development in greater Tucson, Arizona. Ecological Applications 8:680-691.

Gilroy, J. J., and W. J. Sutherland. 2007. Beyond ecological traps: perceptual errors and undervalued resources. Trends In Ecology and Evolution 22:351356.

Girvan, M. K., J. Jones, D. R. Norris, J. J. Barg, T. K. Kyser, and R. J. Robertson. 2007. Longdistance dispersal patterns of male Cerulean Warblers (Dendroica cerulea) measured by stablehydrogen isotopes. Avian Conservation and Ecology - Écologie et conservation des oiseaux 2 (2): 3. [online] URL: http://www.ace-eco.org/vol2/ iss $2 / \operatorname{art} 3 /$.

Greenwood, P. J., and P. H. Harvey. 1982. The natal and breeding dispersal of birds. Annual Review of Ecology and Systematics 13:1-21.

Haas, C. A. 1998. Effects of prior nesting success on site fidelity and breeding dispersal: an experimental approach. Auk 115:929-936.

Hilden, O. 1965. Habitat selection in birds: a review. Annales Zoologici Fennici 2:53-75. 
Johnson, M. D. 2007. Measuring habitat quality: a review. Condor 109:48-504.

Kristan, W. B. III. 2003. The role of habitat selection behavior in population dynamics: sourcesink systems and ecological traps. Oikos 103:457468.

Lancaster, R. K., and W. E. Rees. 1979. Bird communities and the structure of urban habitats. Canadian Journal of Zoology 57:2358-2368.

Marzluff, J. M., R. Bowman, and R. Donnelly. 2001. Avian ecology and conservation in an urbanizing world. Kluwer Academic Publishers, Boston, Massachusetts, USA.

McDonnell, M. J., and S. T. A. Pickett. 1990. Ecosystem structure and function along urban-rural gradients: an unexploited opportunity for ecology. Ecology 71:1232-1237.

Nol, E., C. M. Francis, and D. M. Burke. 2005. Using distance from putative source woodlot to predict occurrence of forest birds in putative sinks. Conservation Biology 19:836-844.

Palomino, D., and L. M. Carrascal. 2006. Urban influence on birds at a regional scale: a case study with the avifauna of northern Madrid province. Landscape and Urban Planning 77:276-290.

Paradis, E., S. R. Baillie, W. J. Sutherland, and R. D. Gregory. 1998. Patterns of natal and breeding dispersal in birds. Journal of Animal Ecology 67:518-536.

Pulliam, H. R. 1988. Sources, sinks, and population regulation. The American Naturalist 132:652-661.

Reed, J. M., and A. P. Dobson. 1993. Behavioral constraints and conservation biology-conspecific attraction and recruitment. Trends in Ecology and Evolution 8:253-256.

Rodewald, A. D., and M. H. Bakermans. 2006. What is the appropriate paradigm for riparian forest conservation? Biological Conservation 128:193200.

Rodewald, A. D., and D. P. Shustack. 2008a. Urban flight: understanding individual and population-level responses of nearctic-neotropical migratory birds to urbanization. Journal of Animal Ecology 77:83-91.

Rodewald, A. D., and D. P. Shustack. 2008b. Consumer resource matching in urbanizing landscapes: are synanthropic species overmatching? Ecology 88:515-521.

Rottenborn, S. C. 1999. Predicting the impacts of urbanization on riparian bird communities. Biological Conservation 88:289-299.

SAS. 2002. SAS system for Windows. Version 9.1. SAS Institute, Cary, North Carolina, USA.

Shochat, E., P. S. Warren, S. H. Faeth, N. E. McIntyre,and D. Hope. 2006. From patterns to emerging processes in mechanistic urban ecology. Trends in Ecology and Evolution 21:186-191.

Sillett, T. S., and R. T. Holmes. 2002. Variation in survivorship of a migratory songbird throughout its annual cycle. Journal of Animal Ecology 71:296308.

Stamps, J. A. 1988. Conspecific attraction and aggregation in territorial species. American Naturalist 131:329-347.

Stamps, J. A., and R. R. Swaisgood. 2007. Someplace like home: experience, habitat selection and conservation biology. Applied Animal Behaviour Science 102:392-409.

Switzer, P. V. 1993. Site fidelity in predictable and unpredictable habitats. Evolutionary Ecology 7:533-555.

Switzer, P. V. 1997. Past reproductive success affects future habitat selection. Behavioral Ecology and Sociobiology 40:307-312.

Tischendorf, L., A. Grez, T. Zaviezo, and L. Fahrig. 2005. Mechanisms affecting population density in fragmented habitat. Ecology and Society 10:7. (online) URL: http://www./ecologyandsociety. org/vol10/iss1/art7/.

Walters, S. 2007. Modeling scale-dependent landscape pattern, dispersal, and connectivity from the perspective of the organism. Landscape Ecology 22:867-881. 
Ward, M. P., and S. Schlossberg. 2004. Conspecific attraction and the conservation of territorial songbirds. Conservation Biology 18:519525.

Weng, Y. C. 2007. Spatiotemporal changes of landscape pattern in response to urbanization. Landscape and Urban Planning 81:341-353.

Westerberg, L., and U. Wennergren. 2003. Predicting the spatial distribution of a population in a heterogeneous landscape. Ecological Modelling 166:53-65.

Whitehead, D. R., and T. Taylor. 2002. Acadian Flycatcher (Empidonax virescens). Number 614 in A. Poole and F. Gill, editors. The birds of North America. American Ornithologists' Union, Cornell Lab of Ornithology, and Academy of Natural Sciences, Philadelphia, Pennsylvania, USA.

Wiens, J. A., N. C. Stenseth, B. Vanhorne, and R. A. Ims. 1993. Ecological mechanisms and landscape ecology. Oikos 66:369-380. 
APPENDIX 1. Development of equations demonstrating that site fidelity coupled with random dispersal of offspring and failed breeders in the context of heterogeneous patch quality can result in different patch densities.

For simplicity we assume the two-patch case with the following parameters for patches A and B.

Patch A:

adult survival rate $=\mathrm{S}_{\mathrm{A}}$ probability of successful reproduction $=\mathrm{R}_{\mathrm{A}}$

number of individuals initially in patch $\mathrm{A}=\mathrm{N}_{\mathrm{A} i}$

Patch B:

adult survival rate $=\mathrm{S}_{\mathrm{B}}$

probability of successful reproduction $=R_{B}$

number of individuals initially in patch $\mathrm{B}=\mathrm{N}_{\mathrm{B} i}$

We assume that successfully reproducing individuals that survive always return to the same patch (i.e., fidelity). Furthermore, we assume that any individuals who fail to reproduce and all offspring are evenly split between patches A and B (i.e., random dispersal). Then we calculate the number of individuals in patch $\mathrm{A}$ and patch $\mathrm{B}$ at time $i+1$ and see if the ratio differs than in time $i$.

The number of individuals from patch $A$ that survive and successfully reproduce $\left(\mathrm{N}_{\mathrm{A} i} \mathrm{SS}\right)$ :

$\mathrm{N}_{\mathrm{A} i} \mathrm{SS}=\mathrm{N}_{\mathrm{A} i} * \mathrm{~S}_{\mathrm{A}} * \mathrm{R}_{\mathrm{A}}$

The number of individuals from patch $A$ that survive and fail to reproduce $\left(\mathrm{N}_{\mathrm{A} i} \mathrm{SF}\right)$ :

$\mathrm{N}_{\mathrm{A} i} \mathrm{SF}=\mathrm{N}_{\mathrm{A} i} * \mathrm{~S}_{\mathrm{A}} *\left(1-\mathrm{R}_{\mathrm{A}}\right)$

The number of offspring produced in patch A (assuming one per successful reproducer) that survive $\left(\mathrm{N}_{\mathrm{A} i} \mathrm{JS}\right) \mathrm{We}$ assume offspring survival is half of adult survival:

$\mathrm{N}_{\mathrm{A} i} \mathrm{JS}=\mathrm{N}_{\mathrm{A} i} * 0.5 * \mathrm{~S}_{\mathrm{A}} * \mathrm{R}_{\mathrm{A}}$

Equations are similar for patch B.

Now to calculate the number of individuals in patch $\mathrm{A}$ in time $i+1$.

$\mathrm{N}_{\mathrm{A} i+1}=\mathrm{N}_{\mathrm{A} i} * \mathrm{~S}_{\mathrm{A}} * \mathrm{R}_{\mathrm{A}}+0.5 *\left[\mathrm{~N}_{\mathrm{A} i} \mathrm{SF}+\mathrm{N}_{\mathrm{A} i} \mathrm{JS}+\mathrm{N}_{\mathrm{B} i} \mathrm{SF}+\mathrm{N}_{\mathrm{B} i} \mathrm{JS}\right]$

Now calculate the number of individuals in patch $\mathrm{B}$ in time $i+1$.

$\mathrm{N}_{\mathrm{B} i+1}=\mathrm{N}_{\mathrm{B} i} * \mathrm{~S}_{\mathrm{B}} *\left(1-\mathrm{R}_{\mathrm{B}}\right)+0.5 *\left[\mathrm{~N}_{\mathrm{A} i} \mathrm{SF}+\mathrm{N}_{\mathrm{A} i} \mathrm{JS}+\mathrm{N}_{\mathrm{B} i} \mathrm{SF}+\mathrm{N}_{\mathrm{B} i} \mathrm{JS}\right]$

Let $\mathrm{X}=0.5 *\left[\mathrm{~N}_{\mathrm{A} i} \mathrm{SF}+\mathrm{N}_{\mathrm{A} i} \mathrm{JS}+\mathrm{N}_{\mathrm{Bi}} \mathrm{SF}+\mathrm{N}_{\mathrm{B} i} \mathrm{JS}\right]$.

Substitute $\mathrm{X}$ into the equations for patches $\mathrm{A}$ and $\mathrm{B}$.

$\mathrm{N}_{\mathrm{A} i+1}=\mathrm{N}_{\mathrm{A} i} * \mathrm{~S}_{\mathrm{A}} * \mathrm{R}_{\mathrm{A}}+\mathrm{X}$

$\mathrm{N}_{\mathrm{B} i+1}=\mathrm{N}_{\mathrm{B} i} * \mathrm{~S}_{\mathrm{B}} * \mathrm{R}_{\mathrm{B}}+\mathrm{X}$

The value of interest is the ratio between the number of individuals in patch A and patch B and whether this changes over time.

$\left(\mathrm{N}_{\mathrm{A} i+1} / \mathrm{N}_{\mathrm{B} i+1}\right)=\left(\mathrm{N}_{\mathrm{A} i} * \mathrm{~S}_{\mathrm{A}} * \mathrm{R}_{\mathrm{A}}+\mathrm{X}\right) /\left(\mathrm{N}_{\mathrm{B} i} * \mathrm{~S}_{\mathrm{B}} * \mathrm{R}_{\mathrm{B}}+\mathrm{X}\right)$ 
This ratio makes it apparent that the values of $S$ and $R$ affect the number of individuals in patches $A$ and B. Unless $S_{A}=S_{B}$ and $R_{A}=R_{B}$ (or some small fraction combinations of $S$ and $R$ that result in the numerator equal to the denominator), differences in the number of individuals in each patch can arise even under random dispersal. 